\title{
Detection of progesterone receptor forms A and B by immunohistochemical analysis
}

\author{
P A Mote, J F Johnston, T Manninen, P Tuohimaa, C L Clarke
}

\begin{abstract}
Aim-The measurement of progesterone receptors $(P R)$ is recommended as part of the clinical management of breast and endometrial cancers, and immunohistochemistry on formalin fixed tissue is now the method of choice. PR is expressed as two isoforms, PRA and PRB, and although both these proteins are expressed in hormone dependent cancers, there is evidence that a large proportion of tumours express a predominance of one isoform. Therefore, it is essential to document the individual detection of PRA and PRB by the presently available anti-PR antibodies. The aim of this study is to investigate the detection of $P R$ isoforms $A$ and $B$ in formalin fixed, paraffin wax embedded cell lines and tissue sections by immunohistochemistry, using a panel of commercial and in house antibodies to human PR.
\end{abstract}

Methods-PR negative cell lines stably transfected to express only PRA (MCF7M11/PRA) or PRB (MDA-MB-231/PRB), and tissue sections of human breast carcinoma and normal endometrium were stained using an immunoperoxidase method. A panel of primary PR specific antibodies was evaluated for ability to detect both PRA and PRB proteins, and for intensity and distribution of positive staining under optimal conditions.

Results-Of the 11 antibodies assessed, only four recognised PRA and PRB similarly. Six recognised PRA proteins but were unable to detect PRB expression in the cell lines expressing only PRA or PRB. In tissues expressing high amounts of PRA and PRB, all antibodies tested demonstrated positive PR staining. However, in tissues expressing a predominance of PRB, differential staining patterns were observed, with variations in staining intensity and in the proportion of cells positive for PR.

Conclusions-Most PR specific antibodies tested failed to detect PRB in formalin fixed tissue by immunohistochemical techniques, despite their ability to do so by immunoblot analysis. These observations suggest that there are conformational differences between PRA and PRB that mask epitopes on the PRB protein recognised by most anti-PR antibodies. The selection of antibodies that recognise both PRB and PRA in formalin fixed tissue is essential for the accurate evaluation of PR positivity in clinical specimens. (f Clin Pathol 2001;54:624-630)

Keywords: progesterone receptor isoforms; progesterone receptor antibodies; immunohistochemistry
The progesterone receptor (PR) is an important prognostic marker in breast cancer, and receptor expression is routinely assessed as an integral part of disease management. In fact, recent guidelines by the American Society of Clinical Oncology recommend oestrogen receptor (ER) and PR measurements only as useful biological markers in breast cancer treatment. ${ }^{1}$ The absence of PR in the primary breast tumour is associated with disease progression, ${ }^{2}$ and may be reflective of an aggressive tumour phenotype. Although evaluation of PR expression is valuable in predicting disease free and overall survival of the patient, ${ }^{3-5}$ it is probably most beneficial in establishing optimal treatment by determining the likelihood of a positive response to endocrine treatment. ${ }^{67}$ Similarly, PR expression in endometrial cancers and ovarian carcinomas is associated with increased survival, ${ }^{89}$ and PR expression in endometrial cancers is associated with a favourable response to progestin treatment. ${ }^{10-12}$

Early measurements of PR in tissues were carried out routinely by biochemical methods, such as the dextran coated charcoal assay, until the production of monoclonal antibodies permitted the development of enzyme immunoassays based on direct recognition of receptor molecules. More recently, during the past decade, immunohistochemical techniques have become popular, to the extent that they are now considered to be the method of choice for the detection of hormone receptors in tissue samples. ${ }^{1314}$ This is primarily the result of the development of reliable antigen retrieval methods, providing a good correlation of results with early techniques, ${ }^{15}{ }^{16}$ and to the widespread availability of commercial antibodies. Moreover, immunohistochemical methods enable the detection of PR in very small tumour samples and in retrospective studies. They also maintain cell integrity, allowing the recognition of non-tumour areas within a sample, and thus avoid aberrant results as a result of neoplastic heterogeneity. Immunohistochemistry is now the preferred method of routinely measuring PR expression in tumours for clinical assessment in most institutions.

PR is a member of a superfamily of ligand activated nuclear transcription factors and is expressed as two isoforms, PRB (116 kDa) and PRA (83 kDa). PRA and PRB are identical except that the shorter PRA form lacks 164 amino acids at the $\mathrm{N}$-terminus. ${ }^{17}$ In vitro studies have shown that PRA and PRB can activate 
different target genes $^{18-24}$ and that PRA, in some circumstances, may act as a dominant inhibitor of the function of PRB, ${ }^{192325}$ and other steroid hormone receptors. ${ }^{26}{ }^{27}$ It is likely that the relative expression of PRA and PRB could determine the cellular response to progesterone.

There is little information to date on PRA and PRB expression in tumours. Although PRA and PRB are both expressed in the normal breast (PA Mote et al, 2000, unpublished), in a proportion of tumours, PRA proteins predominate over $\mathrm{PRB},{ }^{28}{ }^{29}$ and these observations are supported by dual immunofluorescent histochemical analyses of breast and endometrial carcinomas (PA Mote et al, 2000, unpublished). ${ }^{29 a}$ Moreover, most endometrial carcinomas express only one PR isoform, with an equal likelihood of only PRA or only PRB expression. ${ }^{2 a}$ Given the lack of expression of either PRA or PRB in some tumours, and the clinical importance of determining PR positivity in a tumour to facilitate an optimal therapeutic decision, the antibodies used to detect PR proteins by immunohistochemistry should be capable of recognising both isoforms. We have shown recently ${ }^{30}$ that one PR antibody fails to recognise PRB in formalin fixed tissue. In our present study we examine a panel of commercial and in house antibodies for their ability to detect PR, to document their recognition of PRA and PRB using routine immunohistochemical methodology, and we describe the production of a new polyclonal anti-PR antibody.

\section{Materials and methods}

PRODUCTION OF PR-86 ANTIPEPTIDE ANTIBODY

A New Zealand white male rabbit was injected subcutaneously with $100 \mu \mathrm{g}$ of a synthetic peptide conjugated to keyhole limpet haemocyanin to produce anti-PR antibodies. The synthetic peptide (PR-86) located at the C-terminal end of PR corresponds to the peptide sequence 919-933 (NH-Lys-Ile-Leu-Ala-Gly-Met-ValLys-Pro-Leu-Leu-Phe-His-Lys-Lys + additional Cys) of the human PR. ${ }^{31}$ This sequence exists in both $A$ and $B$ isoforms of PR. The first injection contained Freund's complete adjuvant, and the subsequent three injections (at one to two month intervals) contained an incomplete adjuvant. The serum was precipitated with $40 \%$ ammonium sulphate and the resulting IgG fraction, termed PR-86, was further characterised.

TRANSFECTION OF COS CELLS

COS cells (African green monkey kidney cells) were transiently transfected with human PRA and PRB cDNAs using electroporation, as described previously. ${ }^{17}$ COS cells were grown in DMEM/F12 medium supplemented with $10 \%$ fetal bovine calf serum and plated at $50-60 \%$ confluence in Petri dishes after transfection.

CYTOSOL PREPARATION AND IMMUNOBLOTTING Cytosol preparation and immunoblotting were performed as described previously. ${ }^{32}$ In brief, cells were harvested 48 hours after transfection, lysed, and centrifuged, then denatured in sodium dodecyl sulphate (SDS) sample buffer. Equal amounts of protein $(40 \mu \mathrm{g} / \mathrm{lane})$ were resolved in $6.5 \%$ polyacrylamide slab gels containing $0.1 \%$ SDS and transferred to nitrocellulose membrane. The membranes were presaturated with $5 \%$ skimmed milk powder in TBS-Tween (50mM Tris, $0.9 \% \mathrm{NaCl}, \mathrm{pH}$ 8.0, $0.05 \%$ Tween) and then incubated with the primary antibody PR-86 $(5.0 \mu \mathrm{g} / \mathrm{ml})$ in TBSTween containing $1 \%$ skimmed milk powder at $4^{\circ} \mathrm{C}$ overnight. After washing, the membranes were incubated with peroxidase conjugated goat antirabbit antibody (Cappel, West Chester, Pennsylvania, USA) diluted $1 / 40000$ in TBS-Tween with $1 \%$ skimmed milk powder. The peroxidase reaction was visualised using the enhanced chemiluminescence method (ECL; Amersham, Little Chalfont, Buckinghamshire, UK), with exposure times ranging from 1 to 20 minutes.

\section{TISSUE SAMPLES}

Archival, formalin fixed, paraffin wax embedded breast and endometrial tissue was obtained from the department of tissue pathology, Westmead Hospital, Westmead, Australia. Based on the specimen pathology reports the breast tumour was an infiltrating ductal carcinoma. The normal endometrial tissue samples were obtained from women who had undergone hysterectomy for the presence of fibroids, and the samples were reported as being morphologically normal. Menstrual cycle dating was performed according to the criteria of Noyes et $a l .^{33}$ The proliferative stage endometrium was determined to be between days 8 and 10, and the midsecretory phase endometrium between days 20 and 24 of the menstrual cycle. Colon was used as a very low PR expressing control tissue.

\section{ANTIBODIES}

Table 1 lists the antibodies used in our study. The commercially available PR antibodies are: Novocastra, Clone 16, catalogue number NCL-PGR-312 (Novocastra Laboratories Ltd, Newcastle, UK); Santa Cruz, SC538, catalogue number PR(C-19) and SC539, catalogue number PR(C-20) (Santa Cruz Biotechnology, Santa Cruz, California, USA), and Cell Marque, clones hPRa2 and hPRa3, ${ }^{34}$ catalogue number CMC614 (Cell Marque, Austin, Texas, USA). The in house PR antibodies are: hPRa1, hPRa3, hPRa5, hPRa6, and hPRa7 ${ }^{34}$ : the hPRa3 antibody is the same as the hPRa3 component of the Cell Marque reagent; AB52, ${ }^{35}{ }^{36}$ obtained from Professor K Horwitz, University of Colorado, Denver, USA, and PR-86, as described above.

PREPARATION OF TRANSFECTED CELL LINES Breast cancer cell lines transfected with either PRA only (MCF-7Mll/PRA) or PRB only (MDA-MB-231/PRB) have been described previously. ${ }^{30}$ Cells were fixed in formalin and paraffin wax embedded. The cell blocks were prepared as described previously. ${ }^{30}$ 
Table1 Panel of antibodies used to detect human progesterone receptor forms $A$ and $B$ (PRA and PRB) by immunohistochemical analysis

\begin{tabular}{llllll}
\hline Antibody & Source & Host species & $\begin{array}{l}\text { Antibody } \\
\text { isotype }\end{array}$ & Incubation dilution and time & $\begin{array}{l}\text { PR isoform detection } \\
\text { by immunoblot } \\
\text { analysis }\end{array}$ \\
\hline hPRa1 & In house & Mouse & IgG2b & $1 / 2$, overnight & PRA and B \\
hPRa5 & In house & Mouse & IgG1 & $1 / 50$, overnight & PRA and B \\
hPRa7 & In house & Mouse & IgG1 & $1 / 10,2$ hours & PRA and B \\
Novocastra & Novocastra Laboratories, UK & Mouse & IgG1 & $1 / 200,1$ hour & PRA and B \\
SC538 & Santa Cruz Biotechnology, USA & Rabbit & & $1 / 200$, overnight & PRA and B \\
SC539 & Santa Cruz Biotechnology, USA & Rabbit & IgG1 & $1 / 250$, overnight & PRA and B \\
AB52 & In house & Mouse & IgG1 & $1 / 100$, overnight & PRA and B \\
hPRa3 & Inhouse & Mouse & IgGight & PRA and B \\
PR-86 & In house & Rabbit & IgG1 & $1 / 250,4{ }^{\circ}$ C, overnight & PRA and B \\
Cell Marque & Cell Marque, USA & Mouse & IgG2b & $1 / 50$, overnight & PRA and B \\
hPRa6 & In house & Mouse & & & PRB only \\
\hline
\end{tabular}

ANTIGEN RETRIEVAL

Formalin fixed, paraffin wax embedded sections were cut at $2 \mu \mathrm{m}$ using a standard rotary microtome, mounted on to Superfrost Plus slides (Lomb Scientific, Sydney, Australia) to which Mayer albumen adhesive ${ }^{37}$ had been applied, and dried at $37^{\circ} \mathrm{C}$ for 72 hours. This was followed by storage at $4^{\circ} \mathrm{C}$ for a maximum of three weeks. A combination of heat and pressure was used for antigen retrieval, as described previously. ${ }^{38}$ Briefly, immediately before staining, sections were dewaxed, rehydrated to distilled water, and placed in $0.01 \mathrm{M}$ sodium citrate solution ( $\mathrm{pH}$ 6.0). Slides were heated in $0.01 \mathrm{M}$ sodium citrate in a Tuttnauer $2540 \mathrm{EKA}$ autoclave at $121^{\circ} \mathrm{C}, 15$ pounds/ square inch for 30 minutes.

IMMUNOPEROXIDASE STAINING

After antigen retrieval, sections were placed in $3.0 \%$ (vol $/ \mathrm{vol}$ ) hydrogen peroxide for five minutes (to reduce endogenous peroxidase activity), washed, and then blocked for $30 \mathrm{~min}$ utes with normal goat serum (Hunter Antisera, Jesmond, NSW, Australia), diluted $1 / 1$ in phosphate buffered saline (PBS). All incubations were performed at room temperature in a moist chamber. After removal of excess serum, the sections were incubated with a primary antihuman PR antibody in PBS/0.5\% Triton-X 100 (Amresco, Solon, Ohio, USA). The incubation times and dilutions for each primary antibody are given in table 1 . Preliminary experiments were performed to determine the optimal dilution and incubation times for each primary antibody (data not shown). Primary antibody incubation was followed by incubation with a biotinylated goat antimouse or goat antirabbit antibody (Dako, Glostrup, Denmark) and incubation with a streptavidinbiotin-horseradish peroxidase (Zymed, South San Fransisco, USA), or in the case of hPRa6 antibody, with streptavidin-horseradish peroxidase (Amersham Australia Sydney, Australia). PR proteins were visualised using diaminobenzidine (DAB) (Dako). The control sections were treated in the same way except for the replacement of the primary antibody with PBS $/ 0.5 \%$ Triton-X 100 . The PR content was analysed over the entire section. The intensity of staining was graded as follows: neg, no staining; + , weak staining; ++ moderate staining; +++ , strong staining; and ++++ , intense staining.

\section{Results}

Our study examined the ability of a panel of commercial and in house PR antibodies (table 1) to detect both the A and B forms of PR in human cells and tissues, using immunohistochemical techniques. For all primary antibodies tested, with the exclusion of hPRa6, a sensitive, amplified method of immunoperoxidase staining was used to ensure optimal sensitivity. Previous studies have shown that hPRa6 has a high sensitivity for detection of PR in formalin fixed tissues: use of the amplified immunoperoxidase method with this antibody resulted in abundant specific and non-specific staining. To compare hPRa6 with the other antibodies, a less sensitive detection method was used for this antibody. Cells positive for PR proteins demonstrated distinct brown nuclear staining, whereas PR negative cells appeared blue (fig 1). Control cells (no primary antibody) were negative for PR expression (not shown). No positive staining was detected in the colon, except for a low degree of positivity detected with hPRa6, consistent with the known low expression of PR by this tissue.

All of the antibodies used in our study, with the exception of hPRa6, recognised both PR isoforms by immunoblot analysis (table 1). HPRa6 binds to an epitope in the N-terminus unique to PRB, and does not recognise PRA on immunoblot. ${ }^{34}$

\section{CHARACTERISATION OF THE ANTIBODY PR-86} When cytosols from COS cells, transiently transfected with human PRA and PRB, were immunoblotted with the antibody PR-86, both isoforms (PRB and PRA) were detected (fig 2, lanes 2 and 3), whereas the control lane (COS cells transfected with vector only) showed no specific staining (fig 2 , lane 1 ). The specificity of the polyclonal antibody PR-86 in western blots was verified by presaturation of the primary antibody with an excess of corresponding peptide, which abolished the staining (data not shown).

IMMUNOHISTOCHEMICAL DETECTION OF PRA AND PRB IN TRANSFECTED BREAST CARCINOMA CELL LINES

All antibodies were tested for immunohistochemical detection of PR expression in stably transfected breast carcinoma cell lines expressing either PRA (MCF-7M11/PRA) or PRB 


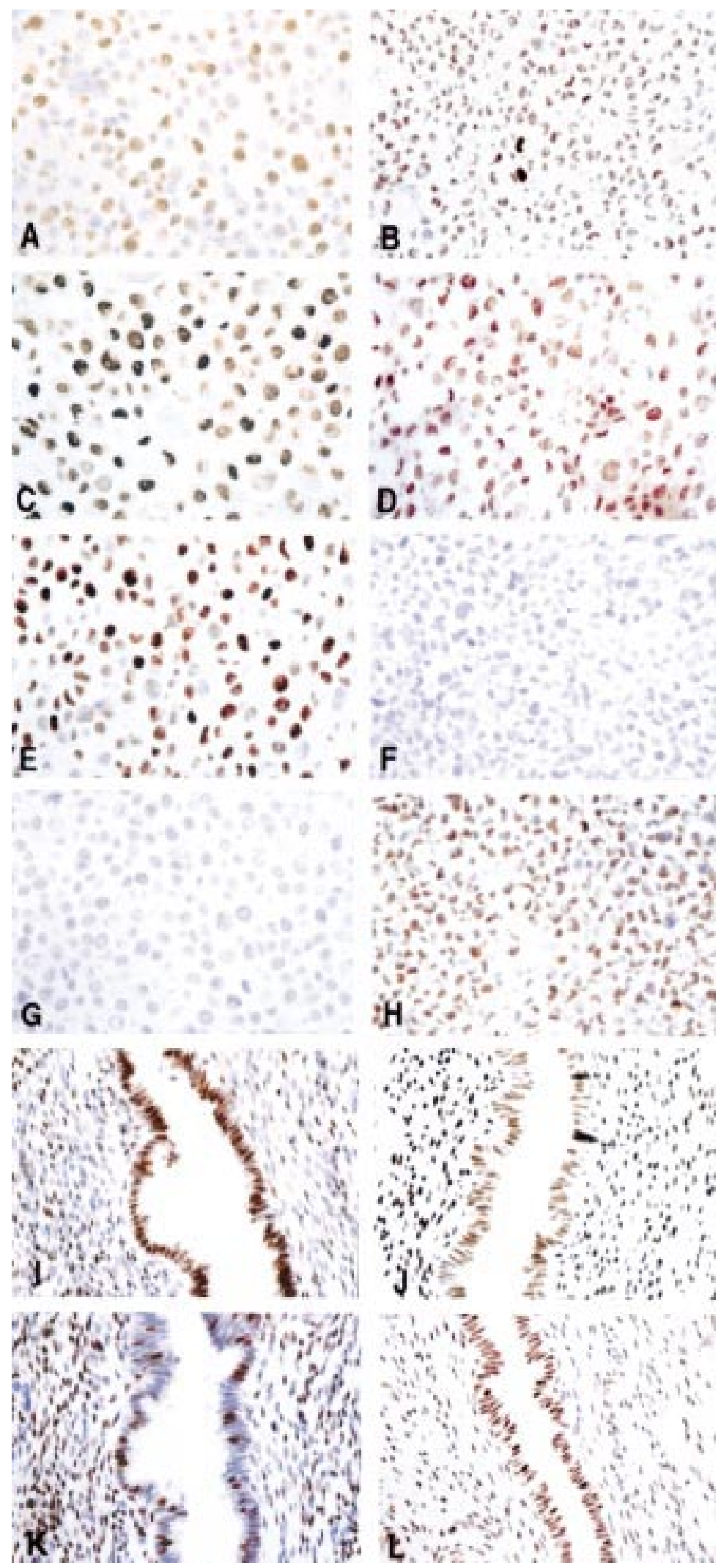

Figure 1 Immunoperoxidase staining of progesterone receptor isoform $A$ and $B$ (PRA and $P R B)$ proteins in a PR negative cell line transfected with PRA (MCF-7M11/PRA) $(A, C$, $E$, and $G) ;$ a PR negative cell line transfected with $P R B(M D A-M B-231 / P R B)(B, D, F$, and $H)$; or midsecretory endometrium $(I-L)$. The primary antibodies used are:- Cell Marque (A, B, and I); PR-86 (C, D, and F); Novocastra (E, F, and $K)$; and hPRa6 ( $G$, $H$, and $L)$. Original magnification, $\times 400$.
(MDA-MB-231/PRB). Ten antibodies recognised PRA and there was no significant difference between the antibodies in the intensity of staining achieved (figs $1 \mathrm{~A}, \mathrm{C}, \mathrm{E}$ ), with the exception of antibody SC539, which produced only modest staining (not shown). Of the 10 antibodies that recognised PRA, six were unable to detect PRB (table 2) - three of these antibodies were obtained from commercial sources (Novocastra, SC538, and SC539) and three were in house antibodies (hPRa1, hPRa5, and hPRa7) (table 2). Only five of the $11 \mathrm{PR}$ antibodies tested detected PRB, and staining with one of these, AB52, was very weak (table 2 ), and less intense when compared with hPRa6, PR-86, and Cell Marque. In addition, one in house antibody, hPRa3, produced only moderate staining (not shown), suggesting that although $\mathrm{AB} 52$ and $\mathrm{hPRa} 3$ recognise both PRA and PRB, they recognise PRA more effectively than PRB.

IMMUNOHISTOCHEMICAL DETECTION OF PR PROTEINS IN PROLIFERATIVE HUMAN ENDOMETRIAL GLANDS AND BREAST TUMOUR To compare antibody staining of $\mathrm{PR}$ in tissues known to express high amounts of both PRA and PRB, nine antibodies were used to stain breast cancer tissue with similar PRA and PRB expression (PA Mote et al, 2000, unpublished), and PRA and PRB expressing epithelial glands of proliferative stage normal endometrium ${ }^{30}$ (table 2). These tissues express high amounts of PR and minimal differences between the antibodies in intensity of PR staining were observed, with the notable exception of SC539, which showed only a moderate staining intensity in proliferative stage endometrial glands (table 2).

IMMUNOHISTOCHEMICAL DETECTION OF PR IN NORMAL MIDSECRETORY ENDOMETRIAL GLANDS We have shown previously that epithelial glands of midsecretory normal endometrium express reduced amounts of PR and many glandular cells during this stage of the menstrual cycle no longer express PRA proteins, whereas most cells in many glands retain expression of PRB. ${ }^{30}$ There was greatly disparate staining between the antibodies in the percentage of epithelial cells positive for PR (table 2; fig 1I-L). Seven of the 11 antibodies tested showed less than one third of the epithelial cells to be PR positive (range, $0-30 \%$ ), and six of these antibodies (hPRa1, hPRa5, hPRa7, Novocastra, SC538, and SC539) also failed to detect PRB expression in the MDA-MB-231/PRB cells (table 2). The exception was hPRa3, which stained only $20 \%$ of the midsecretory glandular cells despite being able to recognise both PRA and PRB in cell lines. However, our previous results (see above) suggest that this antibody does not recognise PRB as efficiently as PRA. The remaining four antibodies (hPRa6, AB52, PR-86, and Cell Marque) stained $>90 \%$ of the glandular epithelial cells (table 2), and three of these antibodies showed intense PRB staining in the transfected cells expressing only PRB. Low intensity staining by $\mathrm{AB} 52$ of most cells supports the view that this antibody can detect 


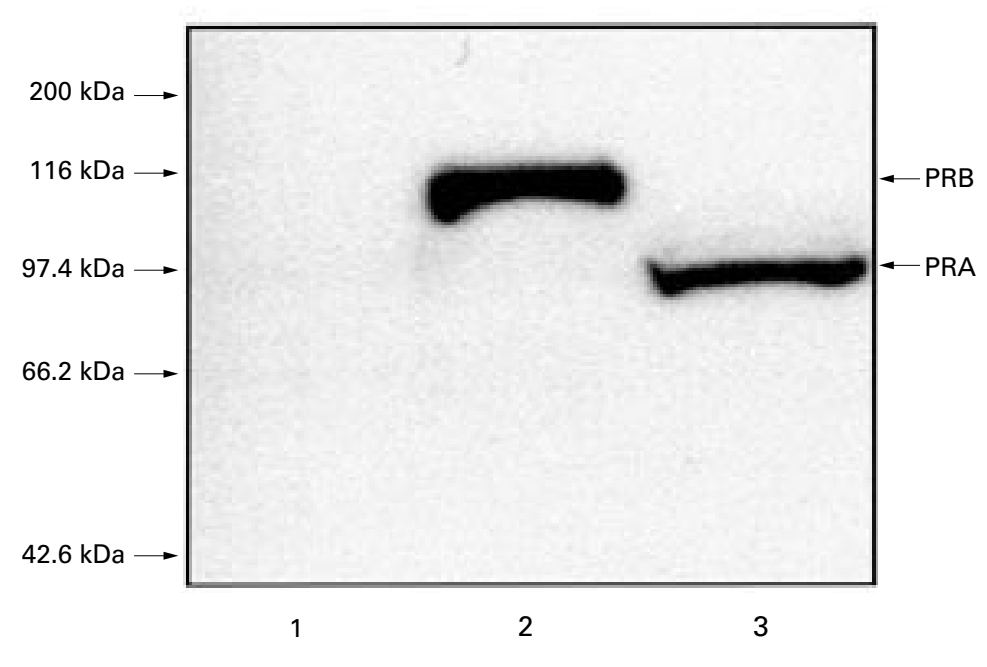

Figure 2 Immunoblot analysis of human progesterone receptor isoforms $A$ and $B$ (PRA and PRB) with PR-86. Equal amounts of total protein from COS cells transfected with human PRA and PRB were analysed by immunoblot using PR-86. Lane 1, negative control (transfected with vector only); lane 2, COS cells transfected with PRB; lane 3, COS cells transfected with PRA.
Increasing numbers of antibodies are available commercially for the measurement of PR in paraffin wax embedded tissue sections, and it is generally assumed that these antibodies will detect both forms of PR proteins. However, our study has shown that not all antibodies can recognise both PRA and PRB proteins with equal efficacy by immunohistochemical methods, and that some antibodies fail to detect PRB at all. Using stably transfected cell lines, expressing either PRA or PRB only, and endometrial glandular epithelium with a loss of PRA expression in some cells, we have demonstrated differential staining patterns when using various antibodies to detect PR.

Of the panel of $11 \mathrm{PR}$ antibodies evaluated in this report, one antibody (hPRa6) recognised only PRB. This antibody binds to an epitope in the $\mathrm{N}$-terminal region of the $\mathrm{PR}$ protein that is unique to the PRB form ${ }^{34}$ and therefore, as would be expected, did not recognise the shorter PRA isoform. Surprisingly, however, six of the remaining antibodies that detected both PRA and PRB by immunoblot analysis failed to reveal PRB in formalin fixed cell lines and tissues. The detection of both PRA and PRB by immunoblot analysis, when proteins are linearised, together with a lack of recognition of $\mathrm{PRB}$ when they are in formalin fixed conformations in tissue sections, strongly implicates the involvement of protein folding. Alternatively, epitope masking could result from the interaction of PRB, but not PRA, with another molecule in vivo before formalin fixation, concealing the crucial antibody recognition site.

As yet, little is known about the three dimensional formation of the $\mathrm{N}$-terminus of PR, but a recent study by Bain et al, using proteolytic peptide mapping, shows that the N-terminal regions shared by PRA and PRB demonstrate distinct ordered structures. ${ }^{39}$ This strongly supports the concept that the $\mathrm{N}$-terminal regions of PRA and PRB have different conformations. Further evidence for differences in the folding of PRA and PRB proteins comes from reports of dissimilar recruitment of cofactors between the two PR isoforms, ${ }^{40}$ differential hormone dependent phosphorylation of the two isoforms, ${ }^{41}$ different influences on the role of the inhibitory function located in a region of the $\mathrm{N}$-terminus shared by ing programmes. ${ }^{13}$

Table 2 Detection of progesterone receptor isoforms (PRA and PRB) in transfected cell lines and human tissues by immunoperoxidase staining

\begin{tabular}{|c|c|c|c|c|c|c|}
\hline \multirow[b]{2}{*}{ Antibody } & \multirow{2}{*}{$\begin{array}{l}\text { PRA expressing } \\
\text { cells }\end{array}$} & \multirow{2}{*}{$\begin{array}{l}\text { PRB expressing } \\
\text { cells }\end{array}$} & \multirow[b]{2}{*}{ Breast cancer } & \multirow{2}{*}{$\begin{array}{l}\text { Proliferative } \\
\text { endometrial glands }\end{array}$} & \multicolumn{2}{|c|}{ Mid secretory endometrial glands } \\
\hline & & & & & Intensity & Cells positive \\
\hline hPRa1 & Yes & No & $++/+++$ & ++++ & $+/++$ & $30 \%$ \\
\hline hPRa5 & Yes & No & $+++/++++$ & ++++ & +++ & $5 \%$ \\
\hline hPRa7 & Yes & No & $++/+++$ & +++ & $+/++$ & $10 \%$ \\
\hline Novocastra & Yes & No & ND & ND & $+++/++++$ & $10 \%$ \\
\hline SC538 & Yes & No & $+++/++++$ & +++ & +++ & $5 \%$ \\
\hline SC539 & Yes & No & $++/+++$ & ++ & - & $0 \%$ \\
\hline AB52 & Yes & Yes/No & +++ & ++++ & ++ & $90-100 \%$ \\
\hline hPRa3 & Yes & Yes & $++/+++$ & ++++ & +++ & $20 \%$ \\
\hline PR-86 & Yes & Yes & +++ & $++/+++$ & $++/+++$ & $90 \%$ \\
\hline Cell Marque & Yes & Yes & ND & ND & +++ & $90 \%$ \\
\hline hPRa6 & No & Yes & ++++ & ++++ & +++ & $100 \%$ \\
\hline
\end{tabular}

The intensity of immunoperoxidase staining for PR was graded as follows: - , no staining; + , weak staining; ++ moderate staining; +++ , strong staining; and ++++ , intense staining. ND, not done. 
both PRA and PRB, ${ }^{42}$ and variable efficacy in intramolecular interactions between the $\mathrm{N}$-terminal and C-terminal regions of PRA and PRB. ${ }^{43}$

The antigen used in the preparation of the monoclonal anti-PR antibody obtained from Novocastra (NCL-PGR-312) consists of a region in the N-terminus of PRA that is conserved between both forms of the protein and is immediately C-terminal to the PRB unique 164 amino acid sequence (Novocastra, 2001, personal communication). However, the epitopes recognised by the other three monoclonal antibodies unable to detect PRB by immunohistochemistry (hPRa1, hPRa5, and hPRa7) have not been determined, although they are known to be in the N-terminal region (R L Balleine, 1999, unpublished observations), and this supports previous studies that have shown that most monoclonal antibodies to $\mathrm{PR}$ recognise epitopes on the $\mathrm{N}$-terminal half of the protein. ${ }^{44}$ This is an area where PRA and PRB are likely to have distinct conformations, and may account for differential recognition of the same epitope on the two forms of PR by some antibodies.

The polyclonal PR antibodies obtained from Santa Cruz recognise an epitope at the C-terminus (SC538), or within an internal domain (SC539) of the human PR, and therefore the detection of PRA and not PRB by immunohistochemistry cannot be fully explained by conformational differences in the common $\mathrm{N}$-terminal region of the two proteins. However, differential association between the C-terminus and the $\mathrm{N}$-terminus of PRA and PRB, reported by Tetal and colleagues, ${ }^{43}$ provides support for differences in the overall conformation of the PRA and PRB proteins that could explain inaccessibility of some epitopes on the folded PRB form in regions other than the $\mathrm{N}$-terminus.

Of the six PR antibodies that failed to detect PRB by immunohistochemistry, the three acquired from commercial sources (Novocastra, SC538, and SC539) were prepared using peptide immunogens that target specific regions of the $\mathrm{PR}^{45}$ (Novocastra and Santa Cruz, 2001, personal communications). It has been shown previously that antibodies produced from synthetic peptide immunogens will bind well to denatured proteins, but may not recognise the protein in its native form. ${ }^{46}$ This is probably because of the concealment of target sequences through protein folding.

Formalin is a widely used fixative that reportedly causes minimal alterations to tissue proteins, and preserves the natural appearance by maintaining a native state. ${ }^{47}$ Conversely, it has also been suggested that formalin fixation results in partial denaturation of proteins, which might affect their tertiary structure. ${ }^{48}$ The mechanisms by which formaldehyde fixes tissue and the extent of protein denaturation that occurs during fixation remain unclear. It is generally accepted that formalin fixation results in the crosslinking of macromolecules, especially proteins, which may conceal antigenic sites from detection by their cognate antibodies, and necessitate epitope unmasking by heat treatment during antigen retrieval. It has been established that the formalin induced crosslinking of proteins preserves secondary structure and protects the molecule from subsequent heat denaturation. ${ }^{49}$ Moreover, restoration of antigenicity by heat treatment may break the methylene bridges formed by formaldehyde fixation crosslinking, allowing proteins to revert to their near normal state. ${ }^{48}$

Our results suggest that heat treatment of formalin fixed tissue produces proteins that exhibit some degree of tertiary structure, where PRA and PRB are differentially folded, and that epitopes recognised by some PR specific antibodies, on regions shared by both isoforms, may be masked on the PRB protein and only accessible on the PRA form. Most anti-PR antibodies are evaluated by immunoblot analysis for their ability to recognise both PRA and PRB proteins; however, we have shown that it does not necessarily follow that these antibodies will still detect both $\mathrm{PR}$ isoforms when the proteins are in their native conformational states.

Where positive staining occurred in tissue sections there were minimal differences in the intensity of immunostaining achieved using different PR antibodies (with the notable exceptions of SC539 and AB52, which performed poorly in the detection of PRA and $P R B$, respectively (table 2)). This was the case regardless of whether or not the antibody could detect both PR isoforms (fig 1I-L). For example, the PR positive cells stained using the Novocastra antibody (PRA only; fig $1 \mathrm{~K}$ ) or hPRa6 (PRB only; fig 1L) are of similar intensity to those stained with PR specific antibodies able to recognise both PRA and PRB (fig 1I,J). A highly sensitive immunohistochemical technique was used in our study, and we suggest that when PRA and PRB proteins are strongly coexpressed within a cell, PRA detection alone reaches saturation level, which results in staining of an equivalent intensity to that observed when both isoforms are revealed. The most important feature of our results is the differential pattern of staining achieved when some cells express only one PR isoform that is not recognised by all antibodies (fig $1 \mathrm{~K}$ ).

We have shown previously that a large proportion of tumours express a predominance of PRA proteins relative to $\mathrm{PRB},{ }^{28}{ }^{29}$ and evidence is emerging that although the PRA and PRB isoforms are both well represented in normal reproductive tissues, loss of expression of one isoform may be a frequent event in breast and endometrial tumour formation (PA Mote et al, 2000, unpublished). ${ }^{29 a}$ It is not currently known whether a predominant expression of PRA or PRB has implications for the response to endocrine treatment, but nevertheless it is important to detect the presence of either isoform because crucial therapeutic decisions may depend upon this information.

In summary, we have shown that most antibodies to PR fail to detect PRB in tissue sections by immunohistochemical techniques, despite their ability to do so by immunoblot analysis. When using some anti-PR antibodies, 
it is possible that PR expression will fail to be detected (or at least will be underestimated) in tissues where PRB is predominant, even when using the most sensitive antigen retrieval and staining techniques.

The authors would like to thank Professor T Ylikomi from the Departments of Cell Biology and Clinical Chemistry, Tampere University Hospital, Tampere, Finland and Dr H Syvälä from the Department of Anatomy, Medical School, University of Tampere, for help in preparation and characterisation of the PR-86 antibody. We also thank Professor K Horwitz from the Department of Medicine and Molecular Biology, University of Colorado Health Sciences Center, Denver, Colorado, USA for Colorado Health Sciences Center, Denver, Colorado, USA for
her kind gift of AB52, and the Department of Tissue Pathology, her kind gift of AB52, and the Department of Tissue Pathology,
Westmead Hospital, Westmead, Australia for supplying the Westmead Hospital, Westmead, Australia for supplying the
archival breast and endometrial samples used in this study. This archival breast and endometrial samples used in this study. This work was supported by the National Health and Medical Research Council of Australia, the Leo and Jenny Leukemia and
Cancer Foundation, the Westmead Millennium Foundation, the Department of Translational Oncology, Westmead and Nepean Hospitals, Westmead, Australia, the Medical Research Fund of Tampere University Hospital, and the Cancer Society of Finland.

1 American Society of Clinical Oncology. 1997 update of recommendations for the use of tumor markers in breast and colorectal cancer. Adopted on November 7, 1997 by the American Society of Clinical Oncology. $f \mathrm{Clin}$ Oncol 1997;16:793-5.

2 Balleine RL, Earl MJ, Greenberg ML, et al. Absence of progesterone receptor associated with secondary breast cancer
in postmenopausal women. Br F Cancer 1999;79:1564-71.

3 Clark GM, McGuire MD. Progesterone receptors and human breast cancer. Breast Cancer Res Treat 1983;3:15763.

4 Clark GM, McGuire WL. Steroid receptors and other prognostic factors in primary breast cancer. Semin Oncol 1988; 15:20-5.

5 Pertschuk LP, Feldman JG, Kim DS, et al. Steroid hormone receptor immunohistochemistry and amplification of c-myc protooncogene. Relationship to disease-free survival c-myc protooncogene. Relationship to dis

6 Pichon MF, Pallud C, Brunet M, et al. Relationship of presence of progesterone receptors to prognosis in early breast cancer. Cancer Res 1980;40:3357-60.

7 Osborne CK. Steroid hormone receptors in breast cancer management. Breast Cancer Res Treat 1998;51:227-38.

8 Rose PG. Endometrial carcinoma. N Engl f Med 1996;335: 640-9.

9 Slotman BJ, Kuhnel R, Rao BR, et al. Importance of steroid receptors and aromatase activity in the prognosis of ovarian cancer: high tumor progesterone receptor levels correlate with longer survival. Gynecol Oncol 1989;33:76-81.

10 Richardson GS, MacLaughlin DT. The status of receptors in the management of endometrial cancer. Clin Obstet in the manecol 1986;29:628-37.

11 Ehrlich CE, Young PCM, Stehman FB, et al. Steroid receptors and clinical outcome in patients with adenocarcinoma tors and clinical outcome in patients with adenocarcinoma 807.

12 Creasman WT. Prognostic significance of hormone receptors in endometrial cancer. Cancer 1993;71:467-70.

13 Taylor CR. An exaltation of experts: concerted efforts in the standardization of immunohistochemistry. Hum Pathol 1994;25:2-11.

14 Battifora H. Immunocytochemistry of hormone receptors in routinely processed tissues. Appl Immunohistochem 1994;2: $143-5$.

15 Cavaliere A, Bucciarelli E, Sidoni A, et al. Estrogen and progesterone receptors in breast cancer: comparison between enzyme immunoassay and computer-assisted image analysis of immunocytochemical assay. Cytometry 1996;26:2048 .

16 Katoh AK, Stemmler N, Specht S, et al. Immunoperoxidase staining for estrogen and progesterone receptors in archival formalin fixed, paraffin embedded breast carcinomas after microwave antigen retrieval. Biotech Histochem 1997;72: microwave 8 .

17 Kastner P, Krust A, Turcotte B, et al. Two distinct estrogenregulated promoters generate transcripts encoding the two functionally different human progesterone receptor forms A and B. EMBO $1990 ; 9: 1603-14$.

18 Kazmi SMI, Visconti V, Plante RK, et al. Differential regulation of human progesterone receptor $\mathrm{A}$ and $\mathrm{B}$ formmediated trans-activation by phosphorylation. Endocrinology 1993;133:1230-8

19 Vegeto E, Shahbaz MM, Wen DX, et al. Human progesterone receptor A form is a cell- and promoter-specific repressor of human progesterone receptor B function. Mol Endocrinol 1993;7:1244-55.

20 Wen DX, Xu YF, Mais DE, et al. The A and B isoforms of the human progesterone receptor operate through distinct signaling pathways within target cells. Mol Cell Biol 1994;14:8356-64.

21 Meyer ME, Quirin-Stricker C, Lerouge T, et al. A limiting factor mediates the differential activation of promoters by
the human progesterone receptor isoforms. $\mathcal{F}$ Biol Chem the human progest

22 Sartorius CA, Melville MY, Hovland AR, et al. A third transactivation function (AF3) of human progesterone receptors located in the unique N-terminal segment of the B-isoform. Mol Endocrinol 1994;8:1347-60.

23 Tung L, Mohamed MK, Hoeffler JP, et al. Antagonistoccupied human progesterone B-receptors activate transcription without binding to progesterone response elements and are dominantly inhibited by A-receptors. Mol Endocrinol 1993;7:1256-65.

24 Tora L, Gronemeyer H, Turcotte B, et al. The N-terminal region of the chicken progesterone receptor specifies target ene activation. Nature 1988;333:185-8.

25 Mohamed MK, Tung L, Takimoto GS, et al. The leucine zippers of c-fos and c-jun for progesterone receptor dimerization: A-dominance in the A/B heterodimer. F Steroid Biochem Mol Biol 1994;51:241-50.

26 McDonnell DP, Goldman ME. RU486 exerts antiestrogenic activities through a novel progesterone receptor A form-mediated mechanism. F Biol Chem 1994;269:119459.

27 McDonnell DP, Shahbaz MM, Vegeto E, et al. The human progesterone receptor A-form functions as a transcriptional modulator of mineralocorticoid receptor transcriptional activity. F Steroid Biochem Mol Biol 1994;48:425-32.

28 Graham JD, Yeates C, Balleine RL, et al. Characterization of progesterone receptor $\mathrm{A}$ and $\mathrm{B}$ expression in human breast cancer. Cancer Res 1995;55:5063-8.

29 Graham JD, Yeates C, Balleine RL, et al. Progesterone receptor A and B protein expression in human breast cancer. F Steroid Biochem Mol Biol 1996;56:93-8.

29a Arnett-Mansfield RL, deFazio A, Wain GV, et al. Relative expression of progesterone receptors $\mathrm{A}$ and $\mathrm{B}$ in endometrioid cancers of the endometrium. Cancer Res 2001;61: 4576-82.

30 Mote PA, Balleine RL, McGowan EM, et al. Co-localization of progesterone receptors A and B by dual immunofluorescent histochemistry in human endometrium during the menstrual cycle. F Clin Endocrinol Metab 1999;84:2963-71.

31 Misrahi M, Venencie PY, Saugier-Veber P, et al. Structure of the human progesterone receptor gene. Biochim Biophys Acta 1993;1216:289-92.

32 Uotinen N, Puustinen R, Pasanen S, et al. Distribution of progesterone receptor in female mouse tissues. Gen Comp Endocrinol 1999;115:429-41.

33 Noyes RW, Hertig AT, Rock J. Dating the endometrial biopsy. Fertil Steril 1950;1:3-25.

34 Clarke CL, Zaino RJ, Feil PD, et al. Monoclonal antibodies to human progesterone receptor: characterization by biochemical and immunohistochemical techniques. Endocrinology 1987;121:1123-32.

35 Estes PA, Suba EJ, Lawler-Heavner J, et al. Immunologic nalysis of human breast cancer progesterone receptors. 1 . Immunoaffinity purification of transformed receptors and production of monoclonal antibodies. Biochemistry 1987; 26:6250-62.

36 Elashry-Stowers D, Zava DT, Speers WC, et al. Immunocytochemical localization of progesterone receptors in breast cancer with anti-human receptor monoclonal antibodies. Cancer Res 1988;48:6462-74.

37 Humason G. Animal tissue techniques, 4th ed. San Francisco: WH Freeman \& Co, 1979

38 Mote PA, Leary JA, Clarke CL. Immunohistochemical detection of progesterone receptors in archival breast cancer. Biotech Histochem 1998;73:117-27.

39 Bain DL, Franden MA, McManaman JL, et al. The $\mathrm{N}$-terminal region of the human progesterone A-receptor. $\mathcal{F}$ Biol Chem 2000;275:7313-20.

40 Giangrande PH, Kimbrel EA, Edwards DP, et al. The opposing transcriptional activities of the two isoforms of the human progesterone receptor are due to differential cofactor binding. Mol Cell Biol 2000;20:3102-15

41 Clemm DL, Sherman L, Boonyaratanakornkit V, et al. Differential hormone-dependent phosphorylation of progesterone receptor A and B forms revealed by a phosphoserine site-specific monoclonal antibody. Mol Endocrinol 2000;14: $52-65$.

42 Hovland AR, Powell RL, Takimoto GS, et al. N-Terminal inhibitory function, IF, suppresses transcription by the A-isoform but not the B-isoform of human progesterone receptors. Biol Chem 1998;273:5455-60.

43 Tetal MJ, Giangrande PH, Leonhardt SA, et al. Hormonedependent interaction between the amino- and carboxylterminal domains of progesterone receptor in vitro and in vivo. Mol Endocrinol 1999;13:910-24.

44 Vu Hai MT, Jolivet A, Ravet V, et al. Novel monoclonal antibodies against human uterine progesterone receptor. Mapping of receptor immunogenic domains. Biochem 1989;260:371-6.

45 Bevitt DJ, Milton ID, Piggot N, et al. New monoclonal antibodies to oestrogen and progesterone receptors effective for paraffin section immunohistochemistry. F Pathol 1997; 183:228-32.

46 Harlow E, Lane D. Immunizations. In: Harlow E, Lane D, eds. Antibodies: a laboratory manual. New York: Cold Spring Harbor Laboratory Publications, 1988:72-5.

47 Artvinli S. Biochemical aspects of aldehyde fixation and a new formaldehyde fixative. Histochem $\mathcal{f}$ 1975;7:435-50.

48 Dapson RW. Fixation for the 1990s: a review of needs and accomplishments. Biotech Histochem 1993;68:75-82.

49 Mason JT, O'Leary TJ. Effects of formaldehyde fixation on protein secondary structure: a calorimetric and infrared spectroscopic investigation. $\mathcal{F}$ Histochem Cytochem 1991;39: $225-9$. 